\title{
O self dialógico em desenvolvimento: um estudo sobre as concepções dinâmicas de si em crianças
}

\author{
Sandra Ferraz de Castillo Dourado Freire $\mathrm{a}^{\mathrm{a}^{*}}$ \\ Angela Uchoa Branco ${ }^{b}$ \\ aUniversidade de Brasília, Faculdade de Educação. Brasília, DF, Brasil \\ 'Universidade de Brasília, Instituto de Psicologia. Brasília, DF, Brasil
}

\begin{abstract}
Resumo: 0 presente estudo investiga as transformações do self no contexto escolar em perspectiva dialógica e desenvolvimental. Apresenta o construto concepções dinâmicas de si (CDS) como unidade de análise do processo de transformação de Kelly, uma estudante de quinto ano em uma escola pública. A metodologia qualitativa e interdisciplinar incluiu observações, entrevistas e sessões de grupo focal. A análise priorizou os episódios de qualificação subjetiva na autonarrativa e nas interações sociais, identificação e categorização dos múltiplos indicadores dos posicionamentos pessoais e análise. Resultados destacam que alguns processos envolvidos na transformação subjetiva das crianças em períodos de transição são caracterizados por significativas alterações nas trajetórias das CDS e indicam que o salto desenvolvimental do self dialógico pode ser realizado pela motivação e pelo desejo de mudança do sujeito, mediante a construção de recursos semióticos socioafetivos integrados a fatores contextuais que atuam como catalisadores e potencializam as CDS em emergência.
\end{abstract}

Palavras-chave: self dialógico, desenvolvimento psicológico, psicologia cultural, crianças.

O presente estudo pretende oferecer um modelo explicativo para os processos de mudança ao longo da ontogênese com base em uma perspectiva sociogenética do desenvolvimento humano, priorizando o caráter dinâmico e dialógico da pessoa inserida em um contexto sociocultural específico durante um período de transição psicológica. As perspectivas sociogenéticas em psicologia consideram que "a sociedade participa no processo em que a pessoa constrói a si mesma e, portanto, consiste em um fator interno e não externo de construção" (Valsiner, 1998, p. 1). Porém, o grande desafio é analisar como ocorrem os processos de mútua constituição sujeito-cultura e como são coconstruídos e vivenciados os sistemas e processos de significação e ressignificação de si e do mundo no contraponto das mediações socioculturais e da internalização ativa dos significados da cultura coletiva. A partir de tais pressupostos, nos interessa particularmente compreender os processos de internalização e significações de si de sujeitos crianças no contexto escolar.

O presente artigo apresenta um estudo de caso para ilustrar tais questões. Trata-se de uma estudante que apresenta significativa transformação subjetiva ao longo do ano letivo, passando de ser considerada a típica aluna-problema aos olhos dos professores à aluna exemplar. $\mathrm{O}$ caso foi extraído de um estudo maior que contou com a imersão no contexto de uma sala de aula de quinto ano, que marca a transição do primeiro para o segundo ciclo do ensino fundamental (Freire, 2008; Branco \& Freire, no prelo). Para contemplar o caráter desenvolvimental e dinâmico das concepções de si, estas

* Endereço para correspondência: sandra.ferraz@gmail.com foram geradas com base em uma metodologia que considerou, além das narrativas e observações de sujeitos específicos, outras fontes de informação de forma integrada.

Diversos estudos abordam a relação entre as experiências de aprendizagem no contexto escolar e o desenvolvimento infantil. $\mathrm{O}$ século XX foi palco da efervescência de teorias e de estudiosos famosos que propuseram modelos explicativos para o desenvolvimento ao longo da vida, especialmente na infância e adolescência (Lerner, 1998). Nos últimos 20 anos, as contribuições da psicologia cultural (Rosa, 2007; Valsiner, 1989, 2007), da psicologia dialógica (Bertau, 2004) e da teoria do self dialógico (Hermans, 2001a, 2001b; Hermans \& Dimaggio, 2004) vêm chamando a atenção para o caráter dinâmico e dialógico da constituição do self e do desenvolvimento humano, propondo modelos conceituais, teóricos e metodológicos que levem em conta a pluralidade do self, seu caráter sociogenético e a dimensão da agencialidade do sujeito. Embora os estudos de Bertau (2004) enfatizem o desenvolvimento do self dialógico na infância, ainda são poucos os que o investigam em contextos de intensa socialização, como ao longo da escolarização.

A partir dessa constatação, assumimos duas considerações importantes para o presente trabalho. Reconhecemos a importância de categorias tais como autoestima e autoconceito para o desenvolvimento do sujeito no contexto escolar, mas consideramos equivocada a ideia de estabelecer (em alguns casos, quantificar) qualidades subjetivas relativamente fixas e gerais de autorreferência. Em segundo lugar, determinado conceito pode ter significados diversos para cada sujeito e pode envolver processos de construção singulares dependendo dos valores e crenças 
dos ambientes socioculturais em que o sujeito se insere. Por isso, situamos o processo de constituição de si na infância e no contexto da escolarização na interface de quatro grandes pilares teóricos: (1) a relação indissociável e complexa entre as experiências de aprendizagem no contexto escolar e o desenvolvimento da criança; (2) a noção de desenvolvimento mediado; (3) a perspectiva de self da teoria do self dialógico (TSD); e (4) a construção de categorias de autorreferência a partir de um modelo sistêmico e dinâmico que dê visibilidade aos processos semiótico-afetivos mediados e possibilite o estudo do desenvolvimento das pessoas em contextos culturais específicos.

\section{A perspectiva do self dialógico}

Embora as pessoas expressem, em suas narrativas cotidianas, concepções acerca de si mesmas mediante a inclusão do outro e mediante recorrentes referências aos relacionamentos e às experiências (Sampson, 1996), é comum que se percebam com um self único e articulado por meio de justificativas individualistas, e não como uma hierarquia de conceitos de autorreferência socialmente construídos (Rosch, 1997). Aparentemente, justificativas de caráter "relacionais" não se popularizaram por falta de uma elaboração expressiva dessa forma de visão. $\mathrm{O}$ fato de haver um grande volume de pesquisas disponibilizando definições acerca da pessoa como indivíduo único e separado dos demais (Sampson, 1996) envolve questões de ordem histórico-cultural e político-ideológica decorrentes da supervalorização do individualismo. Entretanto, a psicologia, inspirada nas teorias sociogenéticas e dialógicas tem buscado analisar o desenvolvimento humano no contexto das relações sociais culturalmente contextualizadas (Valsiner, 2012; Vygotsky, 1991).

A TSD ${ }^{1}$ se delineou e teve rápido desenvolvimento no contexto clínico de psicoterapia com adultos, provocando uma avalanche de investigações sobre o self dialógico a partir de sua divulgação no início dos anos 1990, especialmente por conseguir prover um modelo explicativo que dá visibilidade às questões relacionais. Incluiu a participação do sujeito em diálogo com o psicoterapeuta nos processos de interpretação do self (self-investigation) provendo meios de autoconfrontação. Métodos clínicos foram desenvolvidos para investigar os diferentes posicionamentos pessoais e para acessar aspectos relacionais significativos do self nas experiências cotidianas. Assim, propôs dois instrumentos de análise: o repertório de posicionamentos pessoais (RPP) e o sistema de valoração do self, priorizando a perspectiva relacional, dialógica e dinâmica da pessoa e concebendo o self como um sistema semiótico organizado, expresso e reorganizado na narrativa (Hermans, 2001a, 2001b).

A TSD utiliza o conceito de "I-Self" proposto por W. James e a noção de voz de A. Bakhtin, entendendo esta como unidade de significado, um símbolo, um ponto de

1 Uma revisão mais detalhada acerca da teoria pode ser consultada em Freire e Branco (2016) vista, uma posição pessoal (I-position) ou um "personagem" específico (self-position). Defende que o self dialógico emerge, se define e se materializa por meio de uma multiplicidade de posições pessoais estabelecidas nas interações em tempo e espaço específicos e que há uma forma singular como cada sujeito assume tais posições. A análise atenta, portanto, para a polifonia, uma vez que considera que a narrativa está constituída de vozes, as quais são plurais, contraditórias, conflitantes e mesmo opostas, apesar de relativamente organizadas em um sistema dinâmico (Freire \& Branco, 2016; Hermans \& Dimaggio, 2004).

De acordo com a TSD, o self dialógico de uma pessoa compreende posições em diferentes contextos da sua experiência cotidiana. As diversas posições de self apresentam variados níveis de diálogo entre si. Tomando, por exemplo, uma cliente adulta em seus 30 anos de idade, o psicoterapeuta utiliza a TSD para investigar quais são as posições que o "Eu" assume como esposa, como filha, como mãe, como profissional, como amiga e qual a forma como estes se relacionam de acordo com os significados mobilizados na narrativa. A análise da narrativa valoriza o conjunto de posições em função das experiências concretas da cliente. Em diálogo com o psicoterapeuta, a autorreflexão e a autoanálise favorecem desejos e possibilidades de mudança.

O modelo teórico-metodológico do self dialógico proposto por Hermans e seus colaboradores inspirou a construção de categorias analíticas a partir da relação dos posicionamentos de $I$-Self para o estudo das mudanças do sistema de self para além do contexto clínico, enfatizando o processo da construção semiótica e reflexiva do eu. O desenvolvimento da metodologia aqui proposta, e apresentada a seguir, buscou a identificação e análise de indicadores de posicionamentos de Eu-Self (I-Self positions) presentes nos relatos e reflexões do sujeito, mas também considerou as ações comunicativas e metacomunicativas observadas nas interações sociais no contexto das experiências concretas vivenciadas pelos sujeitos no contexto escolar.

Mas por que propor uma nova categoria? Uma das razões para isso relaciona-se ao fato de que os trabalhos de Hermans resultam do estudo de um contexto muito especifico, o clínico, em que as posições de self (self-positions) são extraídas do RPP de sujeitos adultos. Na metodologia para o estudo das posições de self no contexto da psicoterapia, o sujeito é confrontado com uma lista preparada pelo terapeuta a partir das várias narrativas e identifica posições e valorações que dão origem ao RPP, elaborado com fins terapêuticos e de pesquisa (Hermans, 2001a; Hermans \& Dimaggio, 2004).

\section{Concepções dinâmicas de si: emergência de uma categoria teórico-metodológica de natureza relacional}

A categoria concepções dinâmicas de si (CDS) resultou de uma metodologia desenhada para compreender a dinâmica desenvolvimental de crianças que, na pesquisa realizada (Freire, 2008; Branco \& Freire, no prelo), 
encontravam-se em situação de aprendizagem em face de iminência de transição entre contextos educativos ${ }^{2}$. A pesquisa tomou como ponto de partida o jogo de posicionamentos de self envolvidos nas situações discursivas e de (inter)ação mediadas pelas atividades escolares e seus significados. Usou como marcadores a variação desses posicionamentos quando relacionados às qualificações subjetivas identificáveis. A partir das qualificações referentes a si apresentadas pelas crianças, buscou-se identificar os outros sociais significativos que apareciam em posição dialógica a tais posicionamentos. As atividades e práticas sociais e pedagógicas foram analisadas de acordo com sua forma de organização no tempo e no espaço, dando visibilidade, no plano microgenético, aos processos dialógicos envolvidos na emergência ou negociação dos significados dos posicionamentos pessoais assumidos.

Como alternativa à técnica de autoconfrontação das RPPs, as CDS emergem sem configuração prévia, e sim, mediante análise das narrativas estabelecidas no diálogo com a entrevistadora em diferentes momentos. Depois, os indicadores de CDS são verificados nas observações das interações mediante análise da comunicação e metacomunicação. Assim, as CDS tomam forma e significado na dinâmica da análise de todo o conjunto de dados. Os métodos e instrumentos foram construídos a partir do campo empírico guiados pelos objetivos de pesquisa. A imersão etnográfica ao longo do período da pesquisa se mostrou fundamental para dar sentido às informações construídas em todas as instâncias empíricas: observação naturalística da rotina de sala de aula, grupo focal, primeira entrevista com crianças, observação episódica ou direta, entrevista com professora, entrevista final com crianças, análise documental.

A familiarização com o contexto e com a dinâmica sociocultural possibilitou dar sentido às várias posições nas interações, nas atividades e nas autonarrativas que os participantes da pesquisa empreendiam ao longo das instâncias metodológicas. Essa integração, fundamental ao design metodológico adotado, permitiu compor um quadro mais sistemático dos processos de significação em movimento coconstrutivo no contexto cultural do grupo e na constante configuração do sistema de self dialógico das crianças. Algumas proposições do estudo são ilustradas mediante 0 caso apresentado a seguir.

\section{Caso Kelly}

No início do quinto ano ensino fundamental conhecemos Kelly (nome fictício). Sua história escolar havia sido característica de uma aluna-problema, como ela costumava ser chamada pelos professores da escola até então. Tinha dificuldades de aprendizagem, era indisciplinada e agressiva com os colegas. Explosiva, estava sempre em confusão

2 A escola em que foi realizado o estudo pertence à rede pública de ensino em que o primeiro ciclo (primeiro ao quinto ano) e o segundo ciclo (sexto ao nono ano) são realizados em unidades diferentes. Portanto, ao fim do quinto ano, há a mudança compulsória de escola para os promovidos ao sexto ano. com os meninos que jogavam futebol na quadra da escola no recreio. Frequentava, quase diariamente, a sala da direção e havia sido colocada para o atendimento especial no turno contrário para reforço nas matérias que não acompanhava no tempo regular de classe.

Quando Kelly terminou a quarta série, foi considerada aluna modelo pela professora, colegas e demais profissionais da escola. Das qualidades descritas no relatório individual sobre a trajetória e rendimento escolar realizado pela professora e entregue à família no fim de ano, destacamos:

Envolvimento nas atividades de classe e institucionais, domínio das quatro operações, excelente produção de texto quanto à originalidade, organização, coerência e sequência de ideias, apesar das dificuldades ortográficas. Responsável, solidária, cooperativa, organizada, caprichosa, talentosa artisticamente, comprometida, bondosa, reflexiva, comunicativa, líder, alegre... ${ }^{3}$ (Relatório individual de rendimento)

O leitor pode imaginar que se trate de diferentes sujeitos ou, então, encontre dificuldade para vislumbrar as causas de tamanha mudança na vida de uma criança ao longo de alguns meses. Foi no estudo deste e de outros casos semelhantes que se propôs a categoria CDS e sua caracterização como modelo explicativo das mudanças ocorridas no sistema de self em experiências de intensa socialização e qualificação pessoal. Os relatos apresentados a seguir procuram relacionar as evidências aos fatos apresentados anteriormente, incluindo a participação ativa do sujeito de pesquisa em seu processo de transformação pessoal.

À época da pesquisa, Kelly, uma menina negra, levemente acima do peso, tinha 11 anos e morava em uma cidade de Goiás vizinha ao Distrito Federal com a mãe, o pai, o irmão de nove anos, uma tia por parte de mãe e outra tia por parte de pai. Kelly cursava a quarta série em uma escola pública do ensino fundamental localizada na região central de Brasília. A mãe, doméstica, e o pai, pedreiro, eletricista e mecânico, eram naturais de outros estados brasileiros e imigraram para o Centro-Oeste em busca de trabalho.

Kelly estudou na escola em que foi realizada a pesquisa desde o primeiro ano. Na primeira entrevista, ocorrida em meados do segundo bimestre, destaca enfaticamente não ter repetido nenhum ano. Relata, porém, sua complicada trajetória escolar. Em tom anedótico, Kelly fez um movimento retrospectivo. De maneira muito descontraída, relata episódios de quando entrou na escola: "no primeiro dia que eu cheguei, en briguei com um colega que eu nem conhecia, comecei a estragar os pincéis da professora, risquei tudo!!! (rindo)". Em outro ano, ela diz que fez reforço, no turno contrário às aulas regulares. Sobre esse período, ela fala de forma mais séria, justificando: "é que

3 Foram compilados os qualificativos na ordem que apareceram ao longo do relatório. 
eu estava com um problema em escrita" e revela que outros problemas também contribuíam para o acompanhamento individualizado: "Bom, os outros problemas eu acho que era o comportamento, assim, organização, essas coisas"; "na matemática eu era mais ou menos"; "por causa que [sic] eu não prestava atenção, ficava brincando, em todas as matérias".

Ao falar do quinto ano, Kelly assume uma postura mais reflexiva. Sobre o reforço escolar, foi enfática: "Só que agora eu não faço mais" e sobre os aspectos mencionados acima, afirma “melhorei muito mais!!!”. Balança com a cabeça, demonstrando orgulho. Explica que "agora, eu converso menos, presto mais atenção, estou com uma letra melhor, eu leio rápido...".

Com relação aos assuntos escolares, o diálogo nas duas entrevistas se concentrou nas experiências vivenciadas ao longo do quinto ano. Quando perguntada sobre suas matérias prediletas na primeira entrevista, Kelly respondeu sem hesitar que eram o português e a matemática. Com relação específica ao português, reconheceu suas dificuldades gramaticais "nessas coisas de digrafo, assim, essas coisas..." e disse que não gostava da matéria nos anos anteriores. No entanto, mostra predileção por escrever: "Por causa que $[s i c]$ é legal escrever assim, ler histórias, tentar descobrir o final assim. . . legal...". Quanto à matemática, cujo desempenho nos exercícios individuais (testes) não era muito bom, ela diz que "já acerto bastante", indicando que também "em matemática eu já estou bem melhor". A emergente disposição para com essas duas matérias na quarta série em relação às séries anteriores aparece melhor explicada na segunda entrevista, que ocorreu após o término do ano letivo:

Na matemática, no português, que antes eu pegava, eu. . . me ensinavam, mas depois é como se viesse uma borracha na minha cabeça e apagava tudo. Ai na quarta série [quinto ano], aprendi tudo de novo, aprendi mais ainda, e nessas férias eu ficava pensando no que eu aprendi. . . [a pesquisadora pergunta: “e você não esqueceu?”] Não!!! . . . nas férias, [antes] eu só ficava pensando, quero me divertir, quero brincar, quero pular, mas agora não, agora chego em casa, fico lá parada, vejo uma caneta, quando penso que não, tem uma revista ali ó. Aí eu pego, aí eu imito, passo o lápis, aí quando eu penso que não, dá vontade de escrever mais ainda, como se fosse uma coceira assim na mão, pegar o lápis e escrever... (comunicação pessoal)

O termo "melhor", que aparece com destacada frequência na narrativa de Kelly para explicar o seu estado atual na escola é inicialmente colocado na primeira entrevista seguido da referência ao conjunto de trabalhos realizados individualmente que a professora havia entregado aos estudantes em um envelope enfeitado naquela manhã:

Bom, primeiro, a professora só corrige e não apaga nada. Ela deixa tudo do jeito que está, na ordem certa: fevereiro, março, abril. . a assim. E a gente pega e vê a diferença de fevereiro para agora, essas coisas, para a gente ver o tanto que a gente melhorou. (comunicação pessoal)

Kelly também expande o discurso acerca de suas melhoras escolares e pessoais. O seguinte diálogo entre Kelly e uma das pesquisadoras na segunda entrevista é bem emblemático:

Ai, neste ano [quinto ano], eu melhorei cem por cento. [Pesquisadora: Por que neste ano?] Olha, em primeiro lugar, porque meus colegas perceberam que eu não era daquele jeito. Segundo, a professora C. sempre me dava conselhos e, terceiro, porque eu descobri uma pessoa que eu tinha dentro de mim. [Pesquisadora: Ah, é, quem?] Uma menina maravilhosa, artista, conhecida (risos). (comunicação pessoal)

No rol das matérias menos prediletas estão história e ciências: "Agora, história e ciências eu não gosto porque eu não sei nada de ciências nem de história" e completa como assumindo a sua responsabilidade no processo: "eu não me interesso!!!". Estar interessada é um termo ao qual ela retorna algumas vezes para explicar a sua disposição pela matéria ou conteúdo e também suas atitudes em relação à sua própria aprendizagem. Entre suas estratégias para aprender um assunto novo, ela precisa ficar "bem interessada", e conta: "À tarde eu fico estudando, estudando, eu pego no pé da minha mãe quando precisa a matéria, eu não paro de estudar essa matéria...", "eu fico toda hora na mesa. Quando tem uma palavra muito difícil, eu escrevo várias vezes, começo a ler, escrevo de novo...".

É interessante observar que há uma lógica semelhante na narrativa de Kelly quando fala de sua família. Frequentemente ela articula um jogo de contraposições entre ela e o irmão para afirmar sua própria posição na família e legitimar uma possível identificação com a mãe. Afirma que ela guarda seus pertences quando chega em casa enquanto o irmão deixa tudo jogado. "Se você soubesse quantas vezes ela [a mãe] briga com meu irmão por causa das meias jogadas no chão, você perde a conta! (rindo)... Meu pai disse que ele é o capeta em volta da gente". Na primeira entrevista ela faz referência à agitação física e teimosia do irmão e, na segunda, refere-se às atitudes isentas de prudência, cuidado, organização, zelo, à falta de interesse por brincadeiras "maduras" e por assuntos "sérios" e à falta de autocuidado (alimentação e higiene). Compreendemos que os posicionamentos assumidos nas referências de Kelly aos outros sociais significativos, como o irmão, informam muito sobre o processo de mudança dela. No contraponto às atitudes do irmão estão as atitudes dela, muitas vezes análogas a da mãe, sempre muito ocupada e preocupada com o meio e com os outros, indicando o ser responsável como forte posicionamento de self. 


\section{A participação do outro nas trajetórias das CDS: a importância das práticas pedagógicas}

O reconhecimento público e individualizado realizado pela avaliação informal da professora em sala de aula (Villas Boas, 1993) ocupou, na pesquisa, uma posição das mais importantes para observar a emergência e ressignificação das CDS. No caso, a ação mediada e mediadora da professora foi um dos aspectos mais significativos no desenvolvimento das CDS das crianças. Mesmo sem abrir mão do seu papel necessariamente assimétrico no contexto escolar, a professora manifestava, de diferentes modos, o quanto qualificava seus estudantes como sujeitos ativos e construtivos, legitimando suas contribuições e, sistematicamente, apoiando cada um em seu processo individual de superação de obstáculos e pleno desenvolvimento. Como exemplo, destacou-se em sua atuação: (a) a promoção de motivação intrínseca e estabelecimento de uma relação afetiva com base na reciprocidade, confiança e respeito (justiça e "relação de confiança") (McDermott, 1977); (b) a utilização sistemática do elogio significativo e (c) a legitimação da voz da criança, ouvindo-a, frequentemente conversando sobre a vida pessoal dela em momentos de socialização de atividades ou debates e mesmo associado aos conteúdos específicos trabalhados em sala de aula.

Também se verificou uma estreita relação entre a qualidade da aprendizagem escolar e os sentimentos positivos que estavam na base das CDS de bom estudante e a melhora das relações com os colegas (amizade). Nesse sentido, é possível considerar a participação tanto da professora quanto do grupo de colegas para o processo de formação, mudança e ressignificação das CDS. As variadas influências sobre esses processos parecem ocorrer através de mecanismos motivacionais complexos e de estratégias interacionais que não são diretas. Inclusive, foi interessante notar que além da Kelly, todos os sujeitos que participaram das entrevistas individuais verbalizaram a importância do outro social e o interesse e desejo em modificar determina$\mathrm{da}(\mathrm{s})$ CDS. Muitas mudanças efetivamente observadas no decorrer do período entre uma e outra entrevista evidenciou o quanto a motivação da criança para mudar relaciona-se com o diálogo com os demais, e como é necessário haver um empenho pessoal no sentido das mudanças. Kelly discorreu sobre a própria mudança nos seguintes termos:

... eu acho que eu era muito nervosa. ... que ninguém queria brincar comigo. Eu já cheguei a ficar sozinha, eu era bobinha e chorava toda a hora. .

. Bem, comecei mudando com os conselhos das colegas ... e das professoras. ... Por causa que [sic] eu percebi a chance que eu tinha na vida e não valorizava. (comunicação pessoal)

A existência do Conselho de Classe Participativo na escola investigada representou uma prática de socialização de autoavaliações fundamental à criação de um espaço construtivo para negociações e desenvolvimento de CDS construtivas. Foram momentos em que as reflexões sobre si e sobre os conflitos vivenciados pelas crianças foram valorizadas, dialogizando possíveis CDS e, consequentemente, favorecendo um maior domínio sobre o próprio desenvolvimento e possíveis mudanças no contexto dos valores culturais canalizados. O Conselho - como espaço para autorreflexão e construção de discursos sobre a 'realidade', sobre os outros e sobre si - foi apontado por Kelly e pelos outros sujeitos participantes como muito importante para a promoção de mudanças nas interações e relações entre eles e em relação às suas próprias concepções sobre si, o que foi corroborado pelas professoras.

O caso Kelly revela a centralidade e importância dos comentários públicos da avaliação informal para o desenvolvimento das CDS. Porém, não estamos nos referindo a qualquer comentário público. Referimo-nos àqueles comentários significativos, por outros sociais significativos, em um contexto significativo, comentários relativos a aspectos ou objetos -sempre culturais, sociais e históricos, dotados de afeto e significado - para a pessoa em questão. A qualidade da posição social é conferida no plano da metacomunicação, definida como comunicação específica sobre a qualidade da comunicação entre as pessoas (Branco \& Valsiner, 2004), a qual se estabelece com base na negociação das CDS de cada participante na interação, voltado para um objetivo e vislumbrando uma perspectiva de futuro.

Kelly apresentou exemplos belíssimos em sua narrativa sobre como as construções de algumas CDS estão relacionadas à aprendizagens que integram importantes contextos culturais, família e escola, tendo ao centro a ação da professora:

A professora C. me ensinou que ... [n]a juventude . . a gente vai ter que ser organizada, né? Ai, de repente, quando saía de casa, eu deixava minha cama toda bagunçada. [Agora] Não! Então, antes de sair de casa eu acordo, tomo banho, ai eu arrumo minha cama, já boto minha meia lá no cesto de roupa suja ... minha roupa já não é toda bagun... enrolada, já está tudo dobrado, meus cremes, minhas coisas já estão tudo num saco... (comunicação pessoal)

A caracterização das CDS não é possível mediante a definição de somente uma posição de self e, necessariamente, exige a compreensão das relações internas na dinâmica do sistema semiótico subjetivo de forma ampla. Com isso, podemos, provisoriamente, postular algumas conclusões. Compreendemos que: (1) as CDS são relacionais, contextuais, dinâmicas e plurais; (2) algumas podem levar a integração e outras à fragmentação do sistema de self dialógico; (3) existem CDS contraditórias, ambivalentes e antagônicas; e (4) algumas CDS podem assumir um papel dominante e outras podem ser escondidas por sofisticadas estratégias de autoproteção. Em resumo, os 
processos de estabelecimento e mudança nas CDS são cultural e socialmente mediados, e envolvem a reconstrução de significados baseados na experiência, autorreflexão e nas possibilidades de desenvolvimento, frequentemente associadas ao desejo de mudança.

\section{As CDS como unidade de análise dos processos dialógicos de constituição do self}

Cada CDS pode ser concebida como um campo afetivo semiótico que transita no sistema de self dialógico (Valsiner, 2014). Assim, uma CDS do sistema pode se tornar dominante sobre as demais, tendo em vista a história do sujeito e o contexto sócio afetivo em determinado momento. Para se estudar a qualidade de uma CDS, seu status nas relações existentes no sistema de self e saber o seu grau de resistência à mudança, há que se estudar o seu desenvolvimento e qual o conjunto de fatores internos e externos relacionados ou ainda, que sustentam as CDS específicas ao longo de práticas sociais e relações significativas da criança com outros específicos, nos mais variados contextos de desenvolvimento.

A hipótese central é que o sistema de self dialógico possa ser representado por campos semióticos de acordo com critérios de maior ou menor estabilidade (Valsiner, 2014), e utilizar essa noção para contextualizar o desenvolvimento das CDS do sujeito, ou seja, o posicionamento das variadas CDS no sistema ao longo do tempo. Assim, podemos conceber campos de maior estabilidade e menor estabilidade, mas que não são definidos nem estanques, porque são relativos às CDS mobilizadas no contexto e ligadas às trajetórias (desenvolvimento) que estão em atuação no momento. Em sua trajetória pelo sistema de self dialógico, uma CDS circula por campos de relativa estabilidade e de instabilidade, dependendo dos contextos sociointerativos em que o sujeito se encontra, das implicações afetivas relativas a tempo e espaço e da articulação com as outras CDS que também transitam no sistema. Em função do caráter dialógico e dinâmico do sistema de self, portanto, as CDS não se organizam da mesma forma em todos os contextos, ou situações sociointerativas, e nem sempre se relacionam da mesma forma com as mediações da cultura coletiva.

Em síntese, é importante reiterar que as CDS se referem à dimensão semiótica do self de constituição histórica e dialógica em constante processo de mudança e que podem ser construídas a partir da análise da movimentação nos posicionamentos pessoais emergentes nas autonarrativas e nas interações comunicativas e metacomunicativas.

Diante do exposto, retomamos a premissa de que as CDS estão na base da emergência de posições de Eu-Self (I-Self) específicas, em contínuo movimento dialógico entre si. Os processos dialógicos que se estabelecem entre as CDS e o contexto relacional são mediados pela coconstrução permanente de significados. É o que constatamos nas narrativas e ações das crianças investigadas: as CDS são sempre coconstruídas em relação a alguém (uma ou mais pessoas). Agora, vamos explorar episódios de interação de Kelly com os colegas nos encontros de grupo focal.

Por exemplo, na última sessão de grupo focal (GF), Kelly negociou uma clara posição de discriminação que lhe foi endereçada por dois colegas, com quem ela entrou em conflito. O grupo estava fazendo uma avaliação das sessões anteriores e uma colega afirmava que havia gostado muito, porque ninguém tinha desrespeitado ninguém. Kelly emite um sonoro "Discordo!". Dois dos participantes demonstram, através de gestos, que entenderam o endereçamento de Kelly. Um deles esconde o rosto rindo e o outro pula da cadeira dizendo "Não fiz nada!". Comovida, Kelly articula entre o explícito e o não dito: "Algumas pessoas ficaram me chamando de Rocky Jr. que eu não gosto!!! Ficaram mangando do meu jeito, do meu cabelo!”. O espaço de diálogo do GF permitiu que ela manifestasse sua mensagem aos colegas, negociando o reconhecimento de uma concepção de si em que se percebe como merecedora de respeito e que sabe da discriminação que está sofrendo por ser negra. Em alusão ao personagem delator do conto lido na primeira sessão (Machado de Assis, 1896/2002), Kelly aponta o dedo para um dos meninos implicados no conflito e diz: "Bom, eu aprendi muita coisa. Aprendi que tem que ter respeito de um pelo outro. ..."

Posicionamento semelhante de Kelly surge em outros momentos de interação, em que lhe atribuem uma posição de inferiorização. A seguir, vejamos um trecho em que CDS de Kelly e Alice, outra participante do GF, são negociadas de maneira diversa no diálogo com os colegas:

\footnotetext{
Menino 1: Alice não faz dever de casa. (apontando com o dedo para ela por cima da mesa) Menina 1: É! (vários apontam o dedo para Alice) Menino 2: Mas a Kelly também! (olhar provocador) Kelly: Mas eu bem menos que a Alice. (Fala com ênfase e autoridade, encerrando o assunto) Menina 2: Ela nem faz. Ela [Alice] fica na hora do recreio para fazer.

Menino 3: (Toma a palavra de Menina 2, em pé se dirige para Alice) Ela sempre fica na hora do recreio.

Alguns: $\dot{E}$.

Alice: (Estava apoiada com o cotovelo na mesa e senta-se enrijecida para trás e em tom de protesto, mas logo afunda na cadeira visivelmente abalada e murmurando baixinho) Mas nem toda vez...

Alice se entristece e se abstém de participar nas discussões por um tempo.
}

É interessante observar as (re)ações de Kelly e Alice: enquanto uma rebate as investidas dos colegas que insistem na mobilização de uma CDS que a desqualifica como aluna, a outra silencia e se retira da interação e da atividade. A diferença nas manifestações das duas meninas sugere que as CDS em negociação estão apoiadas em um conjunto de outras CDS que funcionam de forma dialógica e sistêmica: a CDS de "dominadora, briguenta e rebelde" 
de Kelly e a CDS de "submissa, impotente, com sentimento de inferioridade" de Alice. É no diálogo interno (entre as diferentes CDS) e externo (com os colegas) que as CDS se constituem em ambos os espaços (interno e externo). É o fluxo bidirecional do diálogo que confere a possibilidade de mudanças na qualidade dinâmica das CDS. Daí a impossibilidade de tratar as CDS no plano de características ou traços de personalidade, pois estas são, sobretudo, relacionais, dinâmicas, afetivas e dialógicas, e, portanto, eminentemente complexas.

Observamos que o sentimento, ou a dimensão afetiva, ocupa lugar fundamental para a emergência ou para a ressignificação de uma CDS. Quando o sentimento que se configura na base para uma ação - ou mobiliza o sujeito nas interações - é percebido como uma categoria de emoção verbalizável (Valsiner, 2007), então é possível construir uma CDS identificável pela própria criança e por aqueles que com ela convivem. Quando esse sentimento, porém, é da ordem de um campo afetivo hipergeneralizado, sem palavras, maior é a dificuldade de identificar CDS específicas. O que se pode afirmar, entretanto, é que quanto maior a dominância ou relativa estabilidade de uma CDS, mais importante o seu papel na dinâmica da regulação semiótica (Valsiner, 2007) do sistema de self dialógico.

As CDS podem ser consideradas integradoras (ou construtivas) quando promovem a relativa estabilidade do Sistema de Self Dialógico no sentido de promover a valorização de si o desenvolvimento do sujeito, o que ocorre em associação a indicadores de satisfação por parte da criança. Já as CDS fragmentadoras (ou destrutivas) são aquelas que criam obstáculos a esse desenvolvimento, fragmentando o sistema de self dialógico e gerando sentimentos de frustração e desconforto associados à incapacidade para a autorrealização ou participação legítima no contexto. Sendo assim, não é possível de antemão definir uma determinada concepção no sentido de "boa" ou "má" que seja aplicável indiscriminadamente a todas as pessoas, pois há CDS integradora ou destrutiva, sempre, na perspectiva específica do sistema de self dialógico de cada sujeito. Além do mais, um processo de fragmentação pode vir acompanhado de um processo de reestruturação, quando há apoio de recursos psicológicos de natureza semiótico-afetiva disponibilizados ou mediados por outros sociais.

Uma mesma CDS, inclusive, pode fragmentar ou promover a integração do sistema de uma mesma pessoa em tempos históricos diferentes, dependendo do diálogo com as outras CDS e de sua funcionalidade nas interações sociais. A CDS de "dominadora e briguenta" de Kelly, por exemplo, tinha uma ação inicial fragmentadora segundo suas narrativas e a narrativa da professora, confirmada pelo sentimento de frustração. Entretanto, a partir da diminuição da funcionalidade da CDS de "briguenta" em razão da proeminência de uma CDS de boa pessoa, de bondade, a CDS de dominação e controle de Kelly transformou-se em algo similar a "autonomia com iniciativa", que se tornou altamente funcional na integração do seu sistema de self dialógico. É essa autonomia e esse sentimento de segurança, de estar no "controle" que impulsionam Kelly a ajudar, a aconselhar, a estar interessada em promover os colegas e, consequentemente, em promover o seu próprio desenvolvimento.

Na pesquisa, também observamos que as crianças utilizam estratégias psicológicas interessantes como mecanismos de proteção de si (do tipo "face saving"), que escondem CDS potencialmente fragmentadoras ao Sistema de Self Dialógico. Segundo os resultados da pesquisa (Branco \& Freire, no prelo), tais mecanismos de proteção de si podem ocorrer quando: (a) existem CDS impregnadas de sentimentos fortes com os quais as crianças não conseguem lidar ou assumir; (b) as CDS são incompatíveis com os valores sociais, culturais ou morais do grupo. Nesses casos, os mecanismos de proteção de si são mobilizados para evitar sofrimento e possibilitar as interações sociais. Assim, uma CDS pode ser idealizada ou inventada não apenas como estratégia de proteção de si, mas por outras demandas culturais.

Observamos, também, nos casos estudados, a pluralidade das CDS e a funcionalidade das CDS ambivalentes ou antagônicas. A dinâmica das CDS segue um movimento interessante de diferenciação e identificação, onde a criança - ao vivenciar e compreender sua realidade e suas relações - empreende uma posição mais ativa em relação a seu próprio desenvolvimento, em termos de manutenção e/ou modificação de suas CDS. As ambivalências e os antagonismos das CDS, em todos os casos analisados, demonstraram o potencial dinâmico e gerador das tensões entre elas, tensões que pareceram atuar de forma significativa na emergência de novas CDS e na organização do Sistema de Self Dialógico em desenvolvimento.

É nessa perspectiva, de um desenvolvimento originado no conflito de diferentes ordens sociais e psicológicas que as CDS devem ser interpretadas dentro do Sistema de Self Dialógico de cada um, visto que uma CDS pode ter significações diferentes para cada criança. Um exemplo envolvendo as crianças apresentadas nos episódios do grupo focal quanto às CDS de bom estudante: para Alice significa cumprir as responsabilidades com capricho e prestar atenção na aula; para Kelly, significa ajudar os outros com os seus talentos. Para Renato, é ter um bom desempenho e ser capaz de acertar a tarefa; já para Roberto, é o comportamento, a capacidade de evitar conflitos interpessoais e garantir seu lugar de liderança por outras vias. Vê-se aqui claramente como uma aparentemente mesma CDS possui diferentes significados pessoais, subjetivos para cada criança. Mas por que é assim? Compreender a significação atribuída por cada criança a uma CDS específica pode fazer toda a diferença no que tange à atuação dos educadores em relação a cada uma. Estes últimos tendem a conceber que "ser um bom aluno" signifique a mesma coisa para todas as crianças, mas isso não é verdade. Daí ser preciso que os educadores conheçam melhor seus alunos em sua singularidade subjetiva. Isso reforça a ideia do grande equívoco em propor categorias relativamente fixas e independentes do contexto como autoconceitos ou 
autoimagens, pois os processos de significação de si se dão de maneira diversa e plural para cada sujeito.

\section{Considerações finais}

No presente trabalho, buscamos desenvolver e aplicar o construto de CDS associado ao sistema de self dialógico de maneira a contribuir para o estudo do desenvolvimento da criança em um contexto cultural específico. As CDS enfatizam a qualidade do sistema de self dialógico como sistema semiótico não linear, dialógico, dinâmico e aberto constituído por concepções que a pessoa tem de si mesma e que estão em constante desenvolvimento. Por essas características, se fundamenta no pressuposto de que o sistema deve apresentar uma estabilidade relativa e se desenvolver mediante tensões criadas nos processos de construção e transformação, origem e trajetória, das CDS. Compreender os processos que dão origem e estimulam ou favorecem o desenvolvimento de CDS específicas passa, portanto, a merecer especial destaque, particularmente no contexto da família e da escola.

As CDS mantêm uma relação estreita com a noção de posicionamentos de "I-Self" específicos (Hermans, 1987, 1996a, 1996b), em contínuo movimento dialógico entre si em situações de socialização. Têm, como característica principal, o fato de ser da ordem do "percebido" por parte da pessoa, a qual, em maior ou menor grau, é capaz de identificar, ou mesmo de interferir, nos processos dialógicos que se estabelecem entre tais posicionamentos. Além disso, possuem caráter de maior estabilidade, que confere tanto à pessoa quanto àqueles que com ela interagem uma espécie de referência quanto à qualidade subjetiva das suas características. As CDS assumem, assim, um papel importante para o funcionamento das funções psicológicas, mobilizando o sujeito nas interações, sendo possíveis de serem identificadas por aqueles que convivem (e os que são diretamente responsáveis) pela criança em desenvolvimento.

Por meio das CDS, portanto, foi possível estudar aspectos do desenvolvimento de si em crianças e em contextos de intensa socialização, considerando os processos de desenvolvimento do self a partir das narrativas de significação de si na relação com o outro e das observações das dinâmicas interativas envolvendo cada criança. A pesquisa relatada possibilitou identificar CDS geradas e transformadas no âmbito das experiências escolares e compreender que elas dialogam intensamente com os posicionamentos da criança no âmbito familiar. O que vale destacar é que as concepções do sujeito do caso analisado, per se, não se restringiam a definições rígidas de si, pois, na narrativa, sempre faziam referência a experiências e pessoas do espaço externo (Hermans, 2001a). O interesse foi compreender como se processam a significação e ressignificação das CDS, reconhecendo sua dinamicidade em relação aos contextos sociais e situacionais específicos.

Iniciativa e intencionalidade por parte das pessoas em interação são questões importantes no desenvolvimento deste trabalho, porque elucidam a relação entre as CDS, os processos motivacionais e a atuação das crianças e adultos no contexto observado. Para isso, destacamos o conceito de ação e a estrutura funcional da ação no processo de desenvolvimento semiótico. Rosa (2007) explica que a consciência abstrata e seu caráter de agencialidade não são imediatos e sim resultam de um processo histórico da experiência, esta entendida como afetiva e social. A consciência está presente na experiência primária e primitiva, mas, na ontogênese, envolve a presença ativa de generalizações, abstrações e leis resultantes da compreensão dos processos de funcionamento de pessoas, objetos e situações. Essa compreensão é fundamental para orientar as interpretações dos acontecimentos (passado), e a autorregulação das ações do sujeito (presente) adiante da perspectiva do futuro. Assim, a consciência torna-se agente - relacionado à vontade e iniciativa na construção do desenvolvimento humano (futuro).

É nesse sentido que as práticas pedagógicas, especialmente as de caráter avaliativo, podem atuar como momentos de reflexão e autorreflexão (Freire, 1985; Johnston, 1997) para que as experiências escolares se tornem significativas e relacionadas com as CDS coconstruídas pelas crianças. Daí a importância da ação educativa intencional no estabelecimento de contextos significativos, dando visibilidade a objetivos palpáveis como forma de promover CDS potencialmente integradoras das crianças.

As CDS foram propostas e utilizadas como unidade analítica do desenvolvimento do self dialógico. Sua identificação auxiliou melhor conceber e trabalhar no sentido de visualizar e compreender as trajetórias de desenvolvimento do Sistema de Self Dialógico. Ao elaborar teoricamente sobre a inovação metodológica ora apresentada, pensamos haver contribuído para o estudo do tema, como também, de alguma maneira, para a reflexão dos educadores no sentido de reconsiderar as práticas sociais das situações de aprendizagens como momentos preciosos de coconstrução e desenvolvimento das subjetividades.

\section{The development of the dialogical self: a study of the dynamic self conceptions in children}

Abstract: The paper aims at addressing dialogical self development in children within school contexts from a dialogical and developmental perspective. It introduces the construct Dynamic Self Conceptions (DSC) as a unit of analysis concerning developmental change. Here we analyze the case study of Kelly, a fifth grade student in a public school in Brazil. Qualitative and interdisciplinary methodology integrated procedures such as observation, interviews and focal group sessions. The study identified and categorized multiple indicators of personal positioning and analysis considered subject active participation. Analyses focused on information from narratives and social interactions related to self references and evaluations. Results 
suggest that processes involved in children's personal changes may produce meaningful changes in DSC trajectories. They also indicate that dialogical self developmental appears to be intensely connected to one's own motivation and willingness to change, what entailed the construction of socio-affective and semiotic resources that, integrated with contextual factors, may function as catalysts for the emergence of new DSC.

Keywords: dialogical self, development, cultural psychology, children.

\section{Le développement du soi dialogique: une étude de la conception dynamique du soi chez les enfants}

Résumé: Cet article jette un regard sur le changement du soi (self) en contexte scolaire à partir d'une perspective dialogique et développementale. II introduit le construit de Conceptions Dynamiques du Soi (CDS) (Dynamic Self Conceptions) comme l'unité d'analyse concernant le changement du développement de Kelly, une élève du cinquième niveau d'une école publique au Brésil. La méthodologie qualitative et interdisciplinaire a intégré des méthodes telles que d'observation ainsi que des entrevues individuelles et de group (focus group). L'analyse a priorisé des épisodes de qualification personnelle (soi references) circonscrits sur le plan narratif et sur celui des rapports interpersonnels, et d'identification et catégorisation des multiples éléments indticatifs du positionnement personnel des individus. Les résultats obtenus suggèrent que certains processus liés aux changements personnels vécus par l'enfant durant les périodes de transition dénotent des changements significatifs sur le plan des trajectoires liées aux CDS. Ils indiquent encore que l'avancement dans le développement dialogique du soi est fortement est réalisé grâce à la motivation de l'individu et à sa volonté de changement, ce qui implique la construction de ressources socioaffectives et sémiotiques intégrées à des facteurs contextuels fonctionnant comme des catalyseurs et soutenant l'émergence des CDS.

Mots-clés: soi dialogique, développement, psychologie culturelle, enfant.

\section{El desarrollo del self dialógico: estudio de las concepciones dinámicas del self en niños}

Resumen: Esta investigación plantea las transformaciones del self en el contexto escolar en una perspectiva dialógica y de desarrollo. Presenta las Concepciones Dinámicas de sí mismo (CDS) como unidad de análisis del proceso de transformación de Kelly, una estudiante de quinto año primaria de una escuela pública de Brasil. En la metodología cualitativa e interdisciplinar incluyen observaciones, entrevistas y grupo focal. Se identificaron y categorizaron indicadores de los posicionamientos personales. El análisis prioriza episodios de calificación subjetiva en la narrativa y en las interacciones sociales. Los resultados muestran que algunos procesos involucrados en la transformación subjetiva de los niños en transición se caracterizan por alteraciones significativas en las trayectorias de las CDS, y que el desarrollo del self dialógico puede ser realizado por motivación, por deseo de cambio y por construcción de recursos semiótico-afectivos con factores contextuales que actúan como catalizadores y potencializan las CDS en emergencia.

Palabras clave: self dialógico, desarrollo psicológico, psicología cultural, niños.

\section{Referências}

Bertau, M.-C. (2004). Developmental origins of the dialogical self: some significant moments. In H. J. M. Hermans \& G. Dimaggio (Orgs.), The dialogical self in psychotherapy (pp. 29-42). New York, NY: Brunner \& Routledge.

Branco, A. U., \& Freire, S. F. C. D. (no prelo). Dynamic self conceptions: new perspectives to study children's dialogical self development. In M. Han \& P. Cunha (Orgs.), The Subjectified and Subjectifying Mind. Charlotte, NC: Information Age Publishing.

Branco, A. U., \& Valsiner, J. (2004). Communication and metacommunication in human development. Greenwich, CT: Information Age.

Freire, P. (1985). The politics of education: culture, power and liberation. South Hadley, MA: Bergin \& Garvey.
Freire, S. F. C. D. (2008). Concepções dinâmicas de si de crianças em escolarização: uma perspectiva dialógicodesenvolvimental (Tese de doutorado). Instituto de Psicologia, Universidade de Brasília, Brasília, DF.

Freire, S. F. C. D., \& Branco, A. U. (2016). A teoria do self dialógico em perspectiva. Psicologia: Teoria e Pesquisa, 32(1), 25-33.

Hermans, H. J. M. (1987). Self as an organized system of valuations: Toward a dialogue with the person. Journal of Counseling Psychology, 34(1), 10-19.

Hermans, H. J. M. (1996a). Opposites in a dialogical self: constructs as characters. Journal of Constructivist Psychology, 9, 1-26.

Hermans, H. J. M. (1996b). Voicing the self: from information processing to dialogical interchange. Psychological Bulletin, 119(1), 31-50. 
Hermans, H. J. M. (2001a). The construction of a personal position repertoire: method and practice. Culture \& Psychology, 7(3), 323-365.

Hermans, H. J. M. (2001b). The dialogical self: Towards a theory of personal and cultural positioning. Culture \& Psychology, 7(3), 243-282.

Hermans, H. J. M. \& Dimaggio, G. (Eds.) (2004). The dialogical self in psychotherapy. New York, NY: Brunner \& Routledge.

Johnston, P. H. (1997). Knowing literacy: constructive literacy assessment. Portland, ME: Stenhouse Publishers.

Lerner, R. (1998). Theories of human development: contemporary perspectives. In W. Damon \& R. Lerner (Eds.), Handbook of child psychology: theoretical models of human development (pp. 1-24). New York, NY: John Wiley \& Sons.

Machado de Assis, J. M. (2002). Conto de escola (ilustrações: Nelson Cruz). São Paulo: Cosac \& Naify. (Trabalho original publicado em 1896)

McDermott, R. (1977). Social relations as contexts for learning in schools. Harvard Educational Review, 47(2), 198-213.

Rosa, A. (2007). Acts of psyché: Actuations as synthesis of semiosis and action. In J. Valsiner \& A. Rosa (Orgs.), The Cambridge handbook of socio-cultural research (pp. 205-237). New York, Cambridge \& Melbourne: Cambridge University Press.

Rosch, E. (1997). Mindfulness mediation and the private self. In U. Neisser \& D. A. Jopling (Orgs.), The conceptual self in context (pp. 185-202). Cambridge, UK: Cambridge University Press.
Sampson, E. E. (1996). Establishing embodiment in psychology. Theory \& Psychology, 6(4), 601-624.

Valsiner, J. (1989). Human development and culture: the social nature of personality and its study. Lexington, MA: Lexington Books.

Valsiner, J. (1998). The guided mind. Cambridge, MA: Harvard University Press.

Valsiner, J. (2007). Culture in minds and societies: foundations of cultural psychology. New Delhi, India: Sage.

Valsiner, J. (2014). Invitation to cultural psychology. Londres, UK: Sage.

Valsiner, J. (2012). Monuments in our minds: historical symbols as cultural tools. In M. Carretero, M. Asensio \& M. Rodríguez-Moneo, History education and the construction of national identities (pp. 327-349). Charlotte, NC: Information Age Publishing.

Villas Boas, B. M. de F. (1993). Práticas avaliativas e a organização do trabalho pedagógico (Tese de doutorado), Universidade Estadual de Campinas, Campinas, São Paulo.

Vygotsky, L. S. (1991). A formação social da mente. São Paulo, SP: Martins Fontes.
Recebido: $20 / 01 / 2015$

Revisado: 22/03/2016

Aceito: $26 / 04 / 2016$ 